\title{
The analysis of atmospheric factors affecting the value of vertical refraction angle with the assessment of the importance of introduction of the atmospheric amendment
}

\author{
Paulina Kaczor ${ }^{1, *}$ \\ ${ }^{1}$ Wroclaw University of Science and Technology, Faculty of Geoengineering, Mining and Geology, 27 Wyb. Wyspiańskiego St., \\ 50-370 Wroclaw, Poland
}

\begin{abstract}
The study of vertical displacements of hydrotechnical objects, slender constructions, opencast mines or flotation waste reservoirs often requires continuous geodetic monitoring, which in real time defines potential threats resulting from changes in the geometry of the object. In order to ensure high accuracy in determining vertical displacements, a precise robotic tacheometer is used as one of the monitoring sensors. In the case of trigonometric leveling, the quality of measurements is affected not only by the accuracy of the instrument, but also by the centre through which the laser beam emitted by it passes. The radius emitted by the tacheometer due to the layered structure of the atmosphere is deflected, and the angle that it creates with the theoretical course of rays is called the angle of vertical refraction. In order to eliminate the influence of this type of errors, so-called atmospheric correction is introduced to all tacheometric measurements. Currently, total stations automatically determine and introduce corrections for observation, usually using only air temperature and atmospheric pressure. However, the number of factors responsible for the change in atmosphere density, and thus the deflection of the laser beam is much greater. And its influence is also affected by the length of the target and roughness of the area over which the measurement is made. The paper presents the analysis of the significance of various atmospheric and terrain factors that may affect the value of the vertical refraction angle. By the multiple regression method, with the use of the analyzed factors, equations describing the phenomenon of vertical refraction for four seasons have been designated. The defined equation coefficients were used to determine the refraction angle for the observations recorded on the post-flotation waste tank. To confirm the rightness of introducing an additional atmospheric correction, analyses were performed showing the percentage of corrected results.
\end{abstract}

\section{Introduction}

During the determination of displacements of slender, hydrotechnical objects or objects in mining areas, the highest accuracy of measurements is expected. This is due to the need to ensure the safety of people working on objects, as well as people living near such facilities. Detection of the smallest displacements allows to avoid disasters, as well as to protect the object from further displacement and even deformation. Continuous or periodic monitoring is used for this type of measurements. Monitoring systems that continuously perform measurements are based on the tacheometric method, where displacements are determined on the basis of the vertical angle and horizontal distance. The measurements are carried out with high-quality instruments that use the automatic prism targeting algorithms. These algorithms ensure very high precision of measurement, thus eliminating human errors. The external conditions prevailing on the site during the measurement also have a large influence on the observation value. It is necessary to minimize their impact, remembering that these errors cannot be completely eliminated. In the case of a tacheometric method, the biggest problem is the effect of vertical refraction on the value of the vertical angle [1]. To minimize the refraction effect, angular measurements are modified by introducing an atmospheric correction. A lot of methods are used to determine it, the most common of which is the multiple regression method. This method uses the atmospheric conditions prevailing during the measurement, as well as the field conditions in which the measurement is performed, thus determining their share in the value of the correction.

\footnotetext{
*Corresponding author: paulina.kaczor@pwr.edu.pl
} 


\section{Methods}

\subsection{Multiple regression method}

Multiple regression is one of the family of linear regression methods. Linear regression defines a linear relationship between two variables. In the case when more than one factor affects one variable, the multiple regression method is used. One of the assumptions of regression is introducing into the equation of noncorrelated variables. The multiple regression model is represented as follows [2]:

$$
y=\beta_{0}+\beta_{1} \cdot x_{1}+\beta_{2} \cdot x_{2}+\cdots+\beta_{n} \cdot x_{n}+\varepsilon(1)
$$

where:

$y$ - dependent variable

$\beta_{0}$ - constant term (intercept)

$\beta_{1} \ldots \beta_{n}$ - unknown parameters

$x_{1} \ldots x_{n}$ - independent variables

$\varepsilon$ - Standard Error of the Estimate

When determining the atmospheric correction, this method can be used in two ways. The first is to determine the contribution of variables in the equation by determining the coefficients $(B)$ at the known refraction angle $(y)$ and known values of factors $(x)$. The second method relates directly to the determination of the atmospheric correction $(y)$ with known both the coefficients $(B)$ and the values of the explanatory variables.

\subsection{Correlation phenomenon}

The correlation phenomenon examines the interdependence of two variables. To determine the linear force of these relationships, according to the formula no. 2 , the Pearson correlation coefficient is determined.

$$
r_{x y}=\frac{\sum_{i=1}^{n}\left(x_{i}-\bar{x}\right)\left(y_{i}-\bar{y}\right)}{\sqrt{\sum_{i=1}^{n}\left(x_{i}-\bar{x}\right)^{2}} \cdot \sqrt{\sum_{i=1}^{n}\left(y_{i}-\bar{y}\right)^{2}}}
$$

where:

$x_{i}, y_{i}$ - the individual sample points indexed with " $i$ "

$\bar{x}, \bar{y}$ - the sample mean

$n$ - the sample size

The correlation coefficient ranges from -1 to 1 . The negative dependency force determines that the increase in one variable is accompanied by a decrease in the value of the second variable. In the case of an added correlation, the increase of one variable causes the increase of the other. The value of the correlation coefficient due to dependence power is divided into 5 groups [3]:

- $\quad r_{x y}<0.2$ - no linear dependency

- $0.2<r_{x y}<0.4$ - weak dependence

- $0.4<r_{x y}<0.7$ - moderate dependence

- $0.7<r_{x y}<0.9$ - quite strong dependence

- $0.9<r_{x y}<0.9$ - very strong dependence

\subsection{Correlation phenomenon}

During the measurements, the beam sent by the instrument along the path of the instrument-prism, the prism-instrument, is deflected, the reason for this is the phenomenon of vertical refraction. The atmosphere composed of thin layers of different density causes the beam instead of the straight line to form the so-called refraction curve. The extent to which the beam is curved is influenced by many atmospheric and terrain factors. One of the breakdowns of factors affecting the phenomenon of refraction was proposed by Mąkolski [4]. It isolates three groups of factors: atmospheric factors, factors resulting from measurement conditions and indirect factors. The group of atmospheric factors includes: temperature, temperature gradient, pressure, humidity and wind. In this group two dominating factors are distinguished: temperature and atmospheric pressure. Studies show that the value of refractive index increases with the value of atmospheric pressure. Slightly different views occur in the case of dependence of the angle of refraction on the temperature value, in this case it is often referred to the quadratic dependence, sometimes only on the linear relationship. The questionable factor is also the temperature gradient. In case of regression method, should the temperature be replaced with it, and maybe as it is practised in most cases, it should be included in equations with temperature. The next group of factors are the factors resulting from the measurement conditions. They include: target height, horizontal distance and roughness (the area over which the measurement is performed). In his work, Moroz presents the role of the area on which the measurement is performed, presenting the value of refraction angle over various areas (snow, grass, forest bushes) [5]. In many literature examples, this factor is omitted justifying that all measurements are made on the same area, so it is not an indispensable variable. The last group of factors are indirect factors, which include: season of the year and time of the day.

\section{Test stages and their results}

\subsection{Study of the correlation of atmospheric factors}

The first stage of the conducted research was the analysis of the correlation coefficient for variables used in regression equations that will be used to determine the atmospheric correction. The reason for the analysis is the definition of the regression method, which indicates that in the equations there cannot be variables strongly correlated. Among the factors cited in the literature, the temperature and the temperature gradient appear as significant to determine the atmospheric correction to the refraction angle. By definition, the temperature gradient is supposed to be strongly correlated. The experimental object was the meteorological tower of the University of Wrocław, where cyclic temperature measurements have been carried out. At five height levels of the tower $(0.5$ $\mathrm{m}, 1 \mathrm{~m}, 2 \mathrm{~m}, 10 \mathrm{~m}, 15 \mathrm{~m})$, thermometers were placed that recorded the temperature for the next 13 days. In order to 
check the correlation between dependent variables in the regression model, the tests were carried out on a small sample. Measurements were recorded every 15 minutes, and the acquired temperature values at different levels made it possible to determine the temperature gradient. A temperature gradient of $8 \mathrm{~m}$ was calculated from the measured temperature values, this value was obtained by subtracting the temperature values at $10 \mathrm{~m}$ and $2 \mathrm{~m}$ and compared to the temperature at the level of $2 \mathrm{~m}$. For the correlation study, values were chosen at levels that reflected the prevailing terrain conditions on the second object for which data was obtained for the remaining tests. The results of the determined correlation are shown in the Fig. 1.

\section{GRAPH OF TEMPERATURE CORRELATION VALUES FROM THE TEMPERATURE GRADIENT}

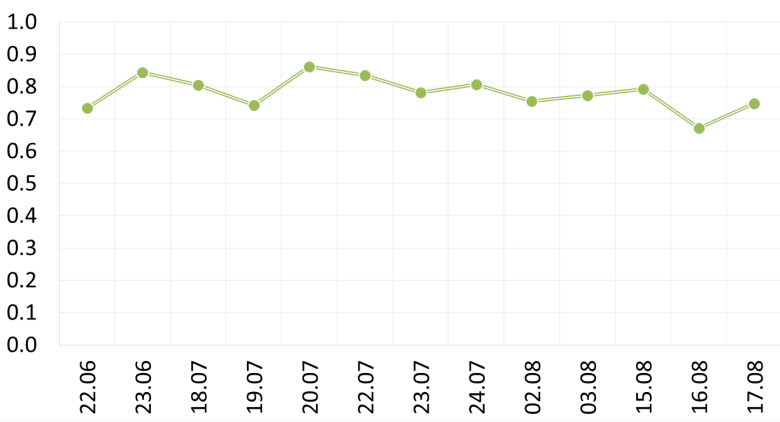

Fig. 1. Graph of temperature correlation values from the temperature gradient.

The results confirm the suspicions, the correlation coefficient in most cases is within the limits of 0.7-0.9, which emphasize quite significant dependence of the variables studied. Therefore, the use of both of these factors in determining the correction for the refractive angle by the multiple regression method is incorrect.

\subsection{Elimination of non-significant factors in regression equations}

In order to obtain information on the significance of introducing individual variables into the equation, including temperature and temperature gradient values, a wider range of data was used. The data used in this process was obtained from the post-flotation waste tank tailings pond, located in Poland in the Lower Silesia Voivodship. The pond is subjected to continuous geodetic observation using the Leica GeoMos system (tacheometric measurement) and periodic geometric levelling measurements [6]. The system provides continuous information, among others, about the vertical angle, the reduced distance and the height of the measured points. The vertical angles obtained directly from the tacheometer and the calculated vertical angles from precision levelling were used to calculate the refraction angle. The vertical angle determined from the levelling was considered to be the true value of the vertical angle.

$$
\delta=V_{\text {real }}-V_{\text {measured }}
$$

where:

$\delta$ - refraction angle

$V_{\text {real }}$ - calculated vertical angles from levelling

$V_{\text {measured }}$ - vertical angles obtained directly from the tacheometer

The monitoring system consists of many different sensors, including a meteorological station, from which data necessary to determine the atmospheric correction were obtained.

The further part of the research, based on the formula no. 1 using it in various combinations. However, the same factors have always been used to create the equation: temperature, temperature gradient, atmospheric pressure, wind, humidity, horizontal distance and target height.

In order to take into account all the suggested factors affecting the value of the refraction angle, the obtained data representing the whole year have been divided. The data division indirectly provided for the inclusion of factors omitted as a variable in the equations. Three variants of the data were used in the analyses. The first of them assumed the division of data only due to the season of the year (summer, autumn, cold, spring). The second option divided the seasons in addition to the time of day (morning, day, evening, night). The last, third option assumed the division of the seasons into high and low (the location of controlled points in relation to the instrument). In the process of data partition, in the winter period a sudden change in the refraction angle was noted. After thorough meteorological analyses it was noticed that the change in the refraction angle was caused by snowfall, therefore the winter period of all variants includes not only the basic division but an additional one, due to the time without snow cover and the period with the snow cover.

The assumption of the research was to determine the regression equations that give the possibility to calculate the value of the correction and to check the correctness of the determination of these equations. In order to do this, data from different time intervals were selected, one data interval was used to determine equations (explanatory data), while the other allowed to check these equations (data explained).

Based on the explanatory data by multiple stepwise regression, further factors were eliminated and included, analysing which of them are significant in the process of determining the atmospheric correction, and which do not contribute much to its value. These analyses were performed for all selected variants, which gave a total of 76 equations. Table 1 compares the significance of the share of dependent factors (temperature gradient, temperature).

The presented results show that in $51 \%$ of equations, temperature plays a more important role than the temperature gradient. However, as many as $27 \%$ are equations with no dominant variable. It shows how thin is the border which occurs between the two analysed variables. In further tests according to the above results, the temperature gradient was eliminated.

In the case of other variables (Table 2) in most equations, all factors used are considered significant. The only exception was the summer period, where humidity 
was only significant in four equations, hence it was eliminated in further studies.

Table 1. The importance of temperature and temperature gradient.

\begin{tabular}{|c|c|c|c|c|c|}
\hline \multirow[b]{2}{*}{ Season } & \multirow{2}{*}{$\begin{array}{l}\text { Temp. - } \\
\text { essential }\end{array}$} & \multirow{2}{*}{$\begin{array}{l}\text { Temp. } \\
\text { gradient - } \\
\text { essential }\end{array}$} & \multicolumn{3}{|c|}{ Statistical analysis } \\
\hline & & & Temp. & $\begin{array}{c}\text { Temp. } \\
\text { gradient }\end{array}$ & Immateria \\
\hline Spring & $3 / 13$ & $3 / 13$ & $1 / 13$ & $0 / 13$ & $6 / 13$ \\
\hline Summer & $6 / 13$ & $0 / 13$ & $5 / 13$ & $0 / 13$ & $1 / 13$ \\
\hline Autumn & $0 / 13$ & $0 / 13$ & $6 / 13$ & $0 / 13$ & $7 / 13$ \\
\hline Winter & $8 / 37$ & $6 / 37$ & $10 / 37$ & $7 / 37$ & $6 / 37$ \\
\hline Immaterial & $\underline{17 / 76}$ & $\underline{9 / 76}$ & $\underline{22 / 76}$ & $\underline{8 / 76}$ & $\underline{20 / 76}$ \\
\hline
\end{tabular}

Table 2. The importance of atmospheric factors.

\begin{tabular}{|c|c|c|c|c|}
\hline Season & Spring & Summer & Autumn & Winter \\
\hline $\begin{array}{c}\text { Atmospheric } \\
\text { pressure }\end{array}$ & $13 / 13$ & $13 / 13$ & $13 / 13$ & $28 / 37$ \\
\hline Wind & $10 / 13$ & $7 / 13$ & $6 / 13$ & $19 / 37$ \\
\hline Humidity & $12 / 13$ & $\mathbf{4} / 13$ & $6 / 13$ & $19 / 37$ \\
\hline $\begin{array}{c}\text { Height of } \\
\text { the prism }\end{array}$ & $9 / 13$ & $13 / 13$ & $13 / 13$ & $28 / 37$ \\
\hline $\begin{array}{c}\text { Horizontal } \\
\text { distance }\end{array}$ & $13 / 13$ & $13 / 13$ & $13 / 13$ & $37 / 37$ \\
\hline
\end{tabular}

\subsection{Determination of regression equations and atmospheric correction for the refraction angle}

Using only significant variables (eliminating the temperature gradient from all seasons and humidity from the summer period) for the explanatory data, coefficients with independent variables were determined. For this purpose, the formula no. 1 was used where the calculated refraction angle was used as the dependent variable $(y)$. The calculated refraction angle is the difference between a vertical angle determined from precise levelling and a vertical angle measured by a tacheometric method. Knowing the coefficients with variables and values of these variables using equation 2 again, corrections to the refraction angle were determined for data from another period (data explained). This time the unknown was the variable $\mathrm{y}$. By adding the correction to the calculated refractive angle, a refractive angle was obtained which was compared to the angle of refraction without correction. If the value of the angle before the correction was greater than the value of the angle after the correction, it was assumed that the refraction angle decreased and the method applied fulfilled its task.

Table 3. Percent of the corrected observations (spring, summer, autumn).

\begin{tabular}{|c|c|c|c|c|c|c|c|c|c|}
\hline & \multicolumn{3}{|c|}{ Spring } & \multicolumn{3}{c|}{ Summer } & \multicolumn{3}{c|}{ Autumn } \\
\hline & total & corrected & $\%$ corrected & total & corrected & $\%$ corrected & total & corrected & $\%$ corrected \\
\hline W3 R_n & 427 & 422 & $\mathbf{9 9 \%}$ & 200 & 200 & $\mathbf{1 0 0 \%}$ & 200 & 195 & $98 \%$ \\
\hline W3 R_w & 437 & 437 & $\mathbf{1 0 0 \%}$ & 220 & 220 & $\mathbf{9 9 \%}$ & 220 & 219 & $\mathbf{1 0 0 \%}$ \\
\hline W3 D_n & 341 & 341 & $\mathbf{1 0 0 \%}$ & 242 & 242 & $\mathbf{1 0 0 \%}$ & 242 & 237 & $98 \%$ \\
\hline W3 D_w & 336 & 336 & $\mathbf{1 0 0 \%}$ & 250 & 250 & $\mathbf{1 0 0 \%}$ & 250 & 250 & $\mathbf{1 0 0 \%}$ \\
\hline W3 W_n & 432 & 425 & $\mathbf{9 8 \%}$ & 310 & 310 & $\mathbf{1 0 0 \%}$ & 310 & 291 & $94 \%$ \\
\hline W3 W_w & 436 & 436 & $\mathbf{1 0 0} \%$ & 329 & 329 & $\mathbf{9 9 \%}$ & 329 & 326 & $99 \%$ \\
\hline W3 N_n & 822 & 763 & $\mathbf{9 3 \%}$ & 670 & 670 & $\mathbf{9 8 \%}$ & 670 & 644 & $96 \%$ \\
\hline W3 N_w & 848 & 799 & $\mathbf{9 4 \%}$ & 809 & 809 & $\mathbf{9 5 \%}$ & 809 & 799 & $99 \%$ \\
\hline
\end{tabular}

Table 4. Percent of the corrected observations (winter).

\begin{tabular}{|c|c|c|c|c|c|c|c|c|c|}
\hline & \multicolumn{9}{|c|}{ Winter } \\
\hline & total & corrected & \% corrected & total & corrected & $\%$ corrected & total & corrected & \% corrected \\
\hline & \multicolumn{3}{|c|}{ without time division } & \multicolumn{3}{|c|}{ from 16.02 to 21.02} & \multicolumn{3}{c|}{ from 04.03 to 08.03 } \\
\hline W3 R_n & 316 & 158 & $50 \%$ & 94 & 84 & $89 \%$ & 116 & 110 & $\mathbf{9 5 \%}$ \\
\hline W3 R_w & 244 & 122 & $50 \%$ & 82 & 80 & $\mathbf{9 8 \%}$ & 120 & 103 & $86 \%$ \\
\hline W3 D_n & 364 & 182 & $50 \%$ & 102 & 95 & $93 \%$ & 147 & 144 & $\mathbf{9 8 \%}$ \\
\hline W3 D_w & 280 & 140 & $50 \%$ & 104 & 103 & $\mathbf{9 9 \%}$ & 167 & 142 & $85 \%$ \\
\hline W3 W_n & 334 & 264 & $\mathbf{7 9 \%}$ & 157 & 142 & $90 \%$ & 177 & 161 & $91 \%$ \\
\hline W3 W_w & 334 & 213 & $64 \%$ & 161 & 159 & $\mathbf{9 9 \%}$ & 173 & 142 & $82 \%$ \\
\hline W3 N_n & 892 & 597 & $67 \%$ & 344 & 315 & $92 \%$ & 548 & 472 & $86 \%$ \\
\hline W3 N_w & 937 & 500 & $53 \%$ & 367 & 354 & $\mathbf{9 6 \%}$ & 570 & 434 & $76 \%$ \\
\hline
\end{tabular}


The above results show that the use of the multiple regression method to determine the atmospheric correction gives satisfactory results. In most periods, this method improves the results of observation in $100 \%$. It is worth noting that the factor often overlooked in determining the atmospheric correction has a very large impact on its value. An example of this is the winter period, where not considering the roughness coefficient improves the data only in 50\%, and its inclusion improves the observation even twice. A similar situation occurs in the case of night hours for the spring and autumn periods, as well as the morning hours of the summer period where local frosts occur (spring and autumn) or morning dew (summer period) thereby changing the absorption of the area that affects the value of refraction angle. The lack of considering this phenomenon in the equations results in the lack of $100 \%$ improvement in results as shown in the tables above.

\section{Discussion and conclusions}

In order to obtain more precise determination of displacements by trigonometric levelling, an atmospheric correction should be used for the measurements. A multiple regression method can be applied to determine it, but only variables independent of each other should be included in it, thus eliminating the temperature gradient or temperature as well as the humidity in the summer. The most important element, and often overlooked, is the variable that is roughness. It should be especially taken into account in the winter period, for example by dividing data into snowy periods and those without a snow cover, as was the case in the research conducted. In the case of long-term measurements of the object, one should not use the regression equations determined in the literature to determine the atmospheric correction, they should first be created. Creating such equations for the tested object will increase the accuracy of elimination of refractive impact. One of the reasons why one should create equations for the tested object is not considering the roughness factor in the equations. The lack of this factor can cause not only the elimination of the refraction effect but even the deterioration of the observation.

Article co-financed from the funds of the Wrocław University of Technology from the Department of Geodesy and Geoinformatics at the Geoengineering, Mining and Geology Department of the statutory order: 0401/0123/17

\section{References}

1. G.A. Kharaghani, Surveying Engineering, TR 132 (1987)

2. R. Tadeusiewicz, A. Izworski, J. Majewski, Biometria (1993)

3. M. Bojańczyk, Kwartalnik Naukowy Uczelni Vistula, 4(38), 74-87 (2013, in Polish)

4. K. Mąkolski, Wpływ środowiska kopalni odkrywkowej na dokładność określenia odległości zenitalnej $i$ wspótrzędnej wysokościowej sieci przestrzennej, $\mathrm{PhD}$ dissertation (1987)

5. О.I. Мороз, Визначення та врахування вертикальної рефракиії під час геодезичних вимірювань (2003)

6. J. Przywara, Geodeta, 04/12, 8-13 (2012) 